\title{
Длительные последовательности афтершоков и эманация гелия: попытка совместного исследования
}

\author{
Асминг В.Э. ${ }^{1}$, Федоров А.В. ${ }^{1}$, Гудков А.В. ${ }^{2}$, Колобов В.В. ${ }^{3}$ Толстихин И.Н. ${ }^{2}$ \\ ${ }^{1}$ Кольский филиал ФИЦ ЕГС РАН, Апатиты \\ ${ }^{2}$ Геологический институт КНЦ РАН, Апатить \\ ${ }^{3}$ Центр физико-технических проблем энергетики Севера КНЦ РАН, Апатиты
}

Аннотация. 21 февраля 2008 года в проливе Стур-фиорд (Шпицберген) произошло сильное землетрясение магнитудой $\mathrm{M}=5.9$, которое сопровождалось беспрецедентно долгой последовательностью афтершоков, продолжающейся по настоящее время. Предполагается, что землетрясение привело к локальному нарушению кристаллического фундамента, подъему мантийных расплавов или их флюидов и повышению давления; разгрузка напряжения происходит через разрушение вмещающих пород и выражается в роях землетрясений. Дегазация расплавов могла привести к появлению мантийного Не в водах Стур-фиорда. Для измерения изотопного состава Не было отобрано несколько проб воды. Специальный комплекс аппаратуры был создан для дегазации вод и очистки Не; измерения были выполнены на модернизированном масс-спектрометре МИ1201ИГ. Отношения ${ }^{3} \mathrm{He} /{ }^{4} \mathrm{He}$ и содержания Не в оказались близкими к таковым, типичным для растворенного атмосферного Не. Пониженные отношения ${ }^{3} \mathrm{He} /{ }^{4} \mathrm{He}$ в одной из проб свидетельствуют о возможном небольшом вкладе терригенного Не, выделяющегося из донных пород. Для продолжения работы требуется специальный рейс исследовательского судна для систематического отбора проб, желательно ранней весной (до полного таяния льдов), когда влияние ветров на перемешивание вод фиорда ограничено.

Ключевые слова: землетрясение, Шпицберген, морская вода, изотоп, гелий.

\section{Long-term aftershock sequence and He emanation: attempt of joint study}

\author{
Asming V.E. ${ }^{1}$, Feodorov A.V. ${ }^{1}$, Gudkov A.V. ${ }^{2}$, Kolobov V.V. ${ }^{3}$, Tolstikhin I.N. ${ }^{2}$ \\ ${ }^{1}$ Kola Department of the Unified Geophysical Survey RAS, Apatity \\ ${ }^{2}$ Geological Institute KSC RAS, Apatity \\ ${ }^{3}$ Northern Energetics Research Centre KSC RAS, Apatity
}

\begin{abstract}
On February 21, 2008, a strong earthquake (magnitude $M=5.9$ ) occurred in the Storfjorden Strait (Spitsbergen), which was followed by an unprecedentedly long sequence of aftershocks, continuing up to now. It is assumed that the earthquake led to a local destruction of the crystalline basement, the rise of mantle melts or their fluids and an increase in pressure. The stresses are released through destructions of host rocks, thus producing swarms of aftershocks. Degassing of the melts could lead to injection of the mantle He in waters of the Storfjord. To measure the He isotopic composition, several water samples have been collected. Special equipment has been produced for degassing of the water samples, and for separation of their $\mathrm{He}$. $3 \mathrm{He} / 4 \mathrm{He}$ ratios and $\mathrm{He}$ concentrations have been measured using modified MI1201IG mass spectrometer. The $3 \mathrm{He} / 4 \mathrm{He}$ ratios and $\mathrm{He}$ concentrations in the samples has proved to be similar to those typical of the dissolved atmospheric He. Reduced $3 \mathrm{He} / 4 \mathrm{He}$ ratios in one of the samples indicate a possible small contribution of terrigenic He released from bottom rocks. To continue this study, a special voyage of a research vessel is required for systematic sampling, preferably in early spring (until the ice melts completely), when mixing of fiord waters is limited.
\end{abstract}

Keywords: isotope, helium, sea water, Spitsbergen.

\section{Введение}

После открытия аномально высокого вклада изотопа ${ }^{3} \mathrm{He}$ в гелий мантии Земли (Мамырин и др. 1969) и последующего накопления экспериментальных данных (Мамырин и Толстихин, 1981) было показано, что частичное плавление мантийных пород и подъем расплавов ответственны за перенос мантийного Не к поверхности Земли. Анализ теплового поля континентальной коры также привел к заключению о принципиальном вкладе внедренных в кору расплавов в формирование тепловых аномалий (Поляк и Смирнов, 1968). Таким образом, формирование и внедрение расплавов 
привело к корреляции геофизических (тепловое поле) и геохимических (изотопия Не) проявлений тектогенеза (Поляк и др., 1979). Внедрение расплавов обычно сопровождается сейсмической активизацией региона, так что с середины 80-х начались сопоставления изотопии Не в природных флюидах и сейсмических событий (Wakita et al., 1987; Gulec et al., 2002; Aydin et al., 2015). Последние также проявляются в разрушении пород земной коры и высвобождении из них радиогенного Не, вариации концентраций которого используются для трассирования сейсмогенных разломов (Ciotoli et al., 1998).

Эти и аналогичные работы стимулировали попытку использовать изотопный состав и концентрацию Не в водах шельфа Стур-фиорд, Шпицберген для суждения о природе наблюдаемой там аномально длительной сейсмической активности. Для такой работы - не выполнявшейся ранее в России - необходимо было разработать методику отбора проб океанической воды, подготовки проб к масс-спектрометрическому анализу и достаточно точного измерения отношений ${ }^{3} \mathrm{He} /{ }^{4} \mathrm{He}$ в гелии морской воды.

\section{О сейсмическом процессе в проливе Стур-фиорд, архипелаг Шпицберген}

21 февраля 2008 года в проливе Стур-фиорд произошло сильнейшее из инструментально зарегистрированных внутриплитных землетрясений этого региона (рис. 1). Событие имело магнитуду $\mathrm{M}=5.9$ и сопровождалось беспрецедентно длинной последовательностью афтершоков (рис. 2).

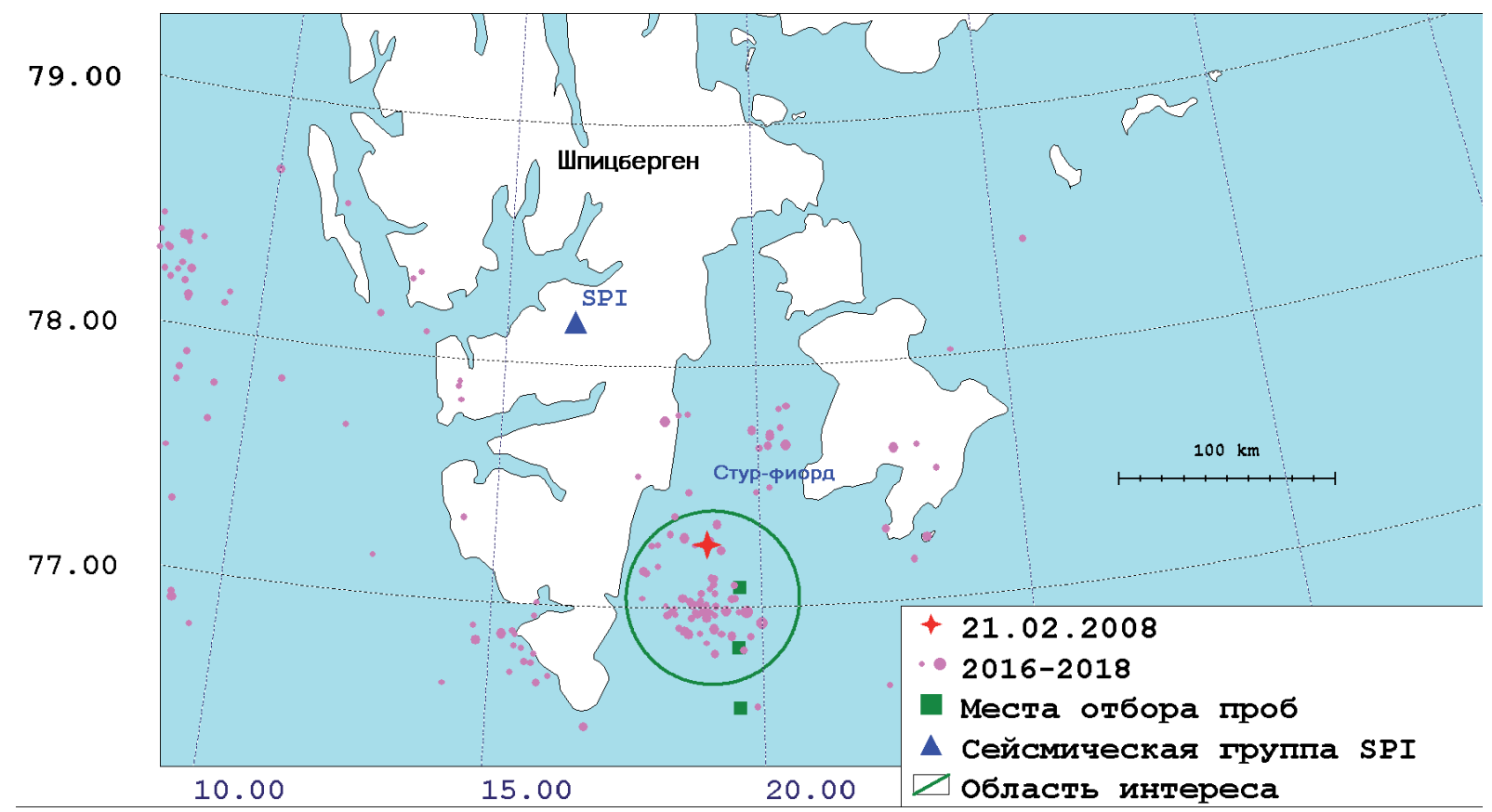

Рис. 1. Положения эпицентра землетрясения, произошедшего 21.02.2008 г. в проливе Стур-фиорд, а также его афтершоков с магнитудами выше 2, наблюдавшихся в 2016-2018 гг. Помечены места отбора проб воды. Пробы отобраны 27 июля 2017 г.

Fig. 1. Epicenter sites of the earthquake that happened in the Storfjorden on 21.02.2008 and its aftershocks with the magnitude $\mathrm{M}>2$ in 2016-2018. Water sampling points are indicated. Water samples were collected on July $27,2017$.

Благодаря наличию сейсмической группы SPI (NORSAR, Норвегия) на расстоянии 150 км от области афтершоков, афтершоковая последовательность была хорошо изучена (Федоров, Асминг, 2011). В полученном распределении количества событий по времени обращают на себя внимание два факта. Первый - затухание афтершокового процесса для событий с $\mathrm{M}>0$ (и даже с $\mathrm{M}>2$ ) соответствует закону Омори, описывающему гиперболическую зависимость уменьшения частоты возникновения афтершоков со временем (Utsu, 1961), лишь до 268-го дня. Затем процесс активизируется, но не резко, как в случае возникновения новой последовательности инициированной силь- 


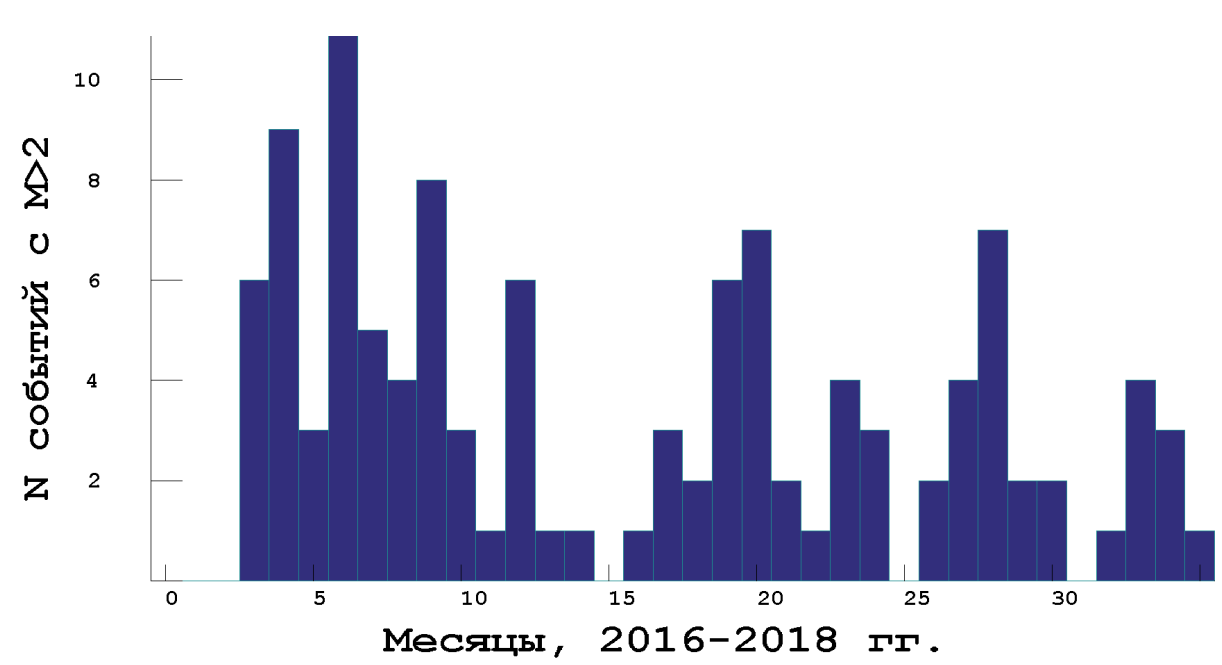

Рис. 2. Временное развитие сейсмического процесса в зоне Стур-фиорд в 2016-2018 гг. для событий с М > 2.

Fig. 2. The seismic activity in the Storfjorden area over time in 2016-2018 for events with the magnitude $M>2$.

ным афтершоком, а плавно. Второй интересный момент - поведение слабых афтершоков с $\mathrm{M}<0$. Заметны периоды их значительной активизации наряду с периодами почти полного отсутствия.

Афтершоковая последовательность в проливе Стур-фиорд не затихла и на момент написания настоящей статьи (январь 2019 года). Так, в 2016-2018 годах здесь произошло около 1900 сейсмических событий с магнитудами до 4.3, из них 18 событий с $\mathrm{M}>3$ и 3 события с $\mathrm{M}>4$. Временное развитие процесса показано на рисунке 2. Виден его квазипериодический характер.

В работе Федорова и соавторов (2012) была предложена следующая модель сейсмического процесса в зоне пролива Стур-фиорд: сильное тектоническое землетрясение 21 февраля 2008 года привело к локальному нарушению архитектуры нижних этажей кристаллического фундамента платформы и, тем самым, к образованию каналов поднятия магматического вещества (флюида). $\mathrm{C}$ течением времени поднимающийся магматический флюид образовал под эпицентральной зоной области повышенного давления и, соответственно, пониженной механической прочности. Разгрузка напряжения в этих областях происходит через разрушение вмещающих пород и выражается в роях землетрясений. Этот механизм предполагает наличие под сейсмической зоной, на глубинах, близких к глубине границы Мохоровича, активного магматического очага. Его дегазация могла бы привести к появлению мантийного Не в водах Стур-фиорда.

\section{Подготовка проб и их масс-спектрометрический анализ}

Для отбора и подготовки проб растворенного в воде Не к масс-спектрометрическому анализу были разработаны и опробованы специальный пробоотборник и комплекс высоковакуумной аппаратуры для дегазации проб и очистки Не и $\mathrm{Ne}$ от паров воды и других газов. Цельностальной пробоотборник многоразового использования состоит из корпуса из нержавеющей стали объемом $160 \mathrm{~cm}^{3}$ и фторопластовой заглушки, предназначенной для герметизации пробоотборника после отбора пробы и для слива воды в дегазационную камеру в условиях высокого вакуума. Для лучшей изоляции отобранной пробы от атмосферного Не использован дополнительный водный затвор, что позволяет обеспечить хранение проб подземных вод в течение нескольких лет.

Установка для дегазации проб воды позволяла выполнять: открытие пробоотборника и слив воды в дегазационную емкость; дегазацию воды, ускоренную за счет ее перемешивания магнитной мешалкой; перевод выделившихся газов через капилляр в емкость, охлаждаемую жидким азотом. Достигнута полнота выделения Не около 99 \%. После дегазации, Не распределяется в линию напуска, очищается от водорода и других химически активных газов и тяжелых инертных газов на ловушках с активированным углем, охлаждаемых жидким азотом, и на $\mathrm{Ti}-\mathrm{Zr}$ геттерах. Вся процедура подготовки пробы к анализу занимает около 60 минут. 
Для измерения изотопных отношений ${ }^{3} \mathrm{He} /{ }^{4} \mathrm{He}$ и концентраций ${ }^{4} \mathrm{He}$ система напуска газов включала три стандарта. Один из них - с близким к атмосферному отношением ${ }^{20} \mathrm{Ne} /{ }^{4} \mathrm{He}-$ для анализа морских, озерных и молодых подземных вод. Второй - с отношением ${ }^{20} \mathrm{Ne} /{ }^{4} \mathrm{He}<<1$ - для анализа газов, выделенных из пород (минералов) и древних подземных вод; третий стандарт предназначен для контроля за первыми двумя.

Измерения выполнялись на масс-спектрометре МИ 1201ИГ с разрешающей способностью 1000 , позволяющей полностью отделить пик ${ }^{3} \mathrm{He}^{+}$от пиков ${ }^{3} \mathrm{H}^{+}$и $\mathrm{HD}^{+}$. Чувствительность по гелию составляет $5 \times 10^{-5} \mathrm{~A}$ торр ${ }^{-1}$, нижний предел измерения для отношений ${ }^{3} \mathrm{He} /{ }^{4} \mathrm{He} \sim 10^{-8}$. Электронное обеспечение масс-спектрометра было модернизировано; в состав нового оборудования вошли: блок управления магнитным полем, блок высоких напряжений, счетчик ионов и электрометры. Были подготовлены и оттестированы программы для автоматизации измерения отношений ${ }^{3} \mathrm{He} /{ }^{4} \mathrm{He}$ и содержания ${ }^{4} \mathrm{He}$, позволяющие сохранять весь процесс измерения в памяти управляющего анализом компьютера. Погрешность определения отношений ${ }^{3} \mathrm{He} /{ }^{4} \mathrm{He}$ составляет $\pm 4 \%(2 \sigma)$. Более подробно методика отбора проб природных вод и определения рассмотрена в работе Гудкова и др. (2014).

\section{Отношения ${ }^{3} \mathrm{He} /{ }^{4} \mathrm{He}$ и содержание Не в водах Cmyр-фиорда}

Отношение изотопов ${ }^{3} \mathrm{He} /{ }^{4} \mathrm{He}$ в проанализированных пробах близко к таковому в растворенном в воде атмосферном гелии, ${ }^{3} \mathrm{He} /{ }^{4} \mathrm{He}=1.37 \times 10^{-6}(\mathrm{~cm}$. таблицу 1$)$. Близкие значения зафиксированы в поверхностных водах озера Имандра (в среднем $1.375 \times 10^{-6}$ ), которые были проанализированы для сравнения с результатами, полученными для вод фиорда. Немного более низкие отношения ${ }^{3} \mathrm{He} /{ }^{4} \mathrm{He}$, отличающиеся от приведенного выше значения на $2 \sigma$, наблюдаются в двух параллельных пробах № 3. Полученные результаты свидетельствуют об отсутствии в изученных пробах измеримого вклада мантийного Не; скорее возможен небольшой вклад радиогенного Не, выделяющегося из донных пород.

Содержания ${ }^{4} \mathrm{He}$ в трех пробах (из 4-х измеренных) не отличаются от типичного для растворенного атмосферного Не $\left(3.99 \times 10^{-8}\right.$ и $4.76 \times 10^{-8} \mathrm{~cm}^{3}$ СТД Не $/ \mathrm{cm}^{3} \mathrm{H}_{2} \mathrm{O}$ в морской и пресной воде, соответственно); небольшой избыток Не в остальных пробах (включая воды озера Имандра) обусловлен растворением пузырьков воздуха.

Таблица 1. Координаты мест отбора проб вод Стур-фиорда, содержания и отношения изотопов гелия в пробах. Для сравнения приведены данные для проб озера Имандра.

\begin{tabular}{|l|c|c|c|c|}
\hline \multicolumn{1}{|c|}{ Место отбора } & $\begin{array}{c}\text { Долгота } \\
(\text { Сев })\end{array}$ & $\begin{array}{c}\text { Широта } \\
\text { (Вост) }\end{array}$ & ${ }^{3} \mathrm{He} /{ }^{4} \mathrm{He} \times 10^{-6}$ & ${ }^{4} \mathrm{He} \times 10^{-8} \mathrm{~cm}^{3} / \mathrm{cm}^{3}$ \\
\hline Стур-фиорд 2 & $77^{\circ} 05.02^{\prime}$ & $19^{\circ} 35.47^{\prime}$ & 1.37 & 3.49 \\
\hline Стур-фиорд 3 & $76^{\circ} 49.84^{\prime}$ & $19^{\circ} 33.83^{\prime}$ & 1.32 & 3.65 \\
\hline Там же & & & 1.31 & 3.34 \\
\hline Стур-фиорд 4 & $76^{\circ} 34.96^{\prime}$ & $19^{\circ} 34.51^{\prime}$ & 1.39 & 4.76 \\
\hline Оз. Имандра & $67^{\circ} 36.47^{\prime}$ & $33^{\circ} 03.75^{\prime}$ & 1.40 & 6.28 \\
\hline Оз. Имандра & $67^{\circ} 36.47^{\prime}$ & $33^{\circ} 03.75^{\prime}$ & 1.35 & 6.69 \\
\hline
\end{tabular}

К сожалению, весьма фрагментарный характер опробования, - малочисленность проб, несистематический характер их отбора, отсутствие разрезов по глубине - не позволяют на данном этапе сделать окончательные выводы. Кроме того, перемешивание вод океана под действием сильных ветров и поверхностных течений достигает глубины 200 м (Schlosser and Winckler, 2002), - соизмеримой с глубиной фиорда. Поэтому полученные результаты не позволяют решить вопрос о наличии / отсутствии в водах фиорда мантийного Не. Можно констатировать, что методика отбора и анализа проб подготовлена и может быть использована. Требуется специальный рейс исследовательского судна для систематического отбора проб, желательно ранней весной (до полного таяния льдов), когда влияние ветров на перемешивание вод фиорда ограничено.

Работа была поддержана грантом РФФИ 18-05-70004 «Ресурсы Арктики». Авторы выражают благодарность Н.И. Мещерякову (Лаборатория океанографии и радиоэкологии ММБИ КНЦ РАН) 
за отбор проб воды в проливе Стур-фиорд в ходе рейса НИС «Дальние Зеленцы». Работы частично выполнены в рамках темы НИР «Развитие методов и аппаратных средств сейсмо-инфразвукового мониторинга процессов деструкции арктической криосферы и обеспечение прогнозирования опасных геодинамических явлений на архипелаге Шпицберген и в прилегающем районе Западного сектора Арктической зоны Российской Федерации».

\section{Литература}

1. Гудков А.В. и др. Тритий-гелий-3 метод и его применение для датирования подземных вод // Геохимия. 2014. № 5. C. 1-8.

2. Мамырин Б.А. и др. Аномальный изотопный состав гелия в вулканических газах // ДАН СССР. 1969. № 184. C. 1197-1199.

3. Мамырин Б.А.,Толстихин И.Н. Изотопы гелия в природе. М. Изд-во: Энергия. 1981. С. 320.

4. Поляк Б.Г., Смирнов Я.Б. Связь глубинного теплового потока с тектоническим строением континентов // Геотектоника. 1968. № 4. С. 3-19.

5. Поляк Б.Г., Толстихин И.Н., Якуцени В.П. Изотопный состав гелия и тепловой поток - геохимический и геофизический аспекты тектогенеза // Геотектоника. 1979. № 5. С. 3-23.

6. Федоров А.В., Асминг В.Э. Результаты изучения трехгодичной сейсмической активности зоны пролива Стур-фиорд, архипелаг Шпицберген // Матер. VI Международной сейсмологической школы «Современные методы обработки и интерпретации сейсмологических данных». Обнинск. Изд-во: ГС РАН. 2011. C. $335-339$.

7. Федоров А.В., Асминг В.Э., Евтюгина 3.А. О возможной природе сейсмического процесса зоны пролива Стур-фиорд. Наука и образование. 2012 [Электронный ресурс]. Матер. международной научнотехнической конференции. Мурманск. 2-6 апреля 2012 г. Мурман. гос. тех. ун-т. Электрон. текст. дан. (Мб). Мурманск: МГТУ. 2012. Электрон. текстподгот. ФГОУВПО «МГТУ». НТЦИн-формрегистр № 0321201101. C. 204-207.

8. Aydin $\mathrm{H}$., et al. Post-earthquake anomalies in $\mathrm{He}-\mathrm{CO}_{2}$ isotope and relative abundance systematics of thermal waters: The case of the 2011 Van earthquake, eastern Anatolia, Turkey // Chem. Geol. 2015. V. 411. P. 1-11.

9. Ciotoli G., et al. Soil gas survey for tracing seismogenic faults: A case study in the Fucino basin, Central Italy // J. Geophys. Res. 1998. V. 103. P. 23,781-23,794.

10. Gulec N.,et al., Helium isotope variations in Turkey: relationship to tectonics, volcanism and recent seismic activities // Chem. Geol.2002. V. 187. P. 129-142.

11. Schlosser P., Winckler G. Noble gases in oceanic waters and sediments // In: Porcelli, D., Ballentine, C.J., Wieler, R. (Ed.), Noble gases in geochemistry and cosmochemistry. 2002 / Mineral. Soc. Amer., Washington.

12. Utsu T. A statistical study on the occurrence of aftershocks // Geophysical Magazine. 1961. V. 30. P. 521-605.

13. Wakita H., et al. High ${ }^{3} \mathrm{He}$ emanation and seismic swarms observed in a nonvolcanic, forearc region // J. Geophys. Res.1987. V. 92. P. 12539-12546. 